\title{
UPDATING THE DESIGN MAP OF FROST INDEXES AS A PREREQUISITE FOR RELEVANT ASSESS- MENT OF TRACK SUBSTRUCTURE FOR NON- TRAFFIC LOAD
}

\author{
Libor IŽVOLT ${ }^{1}$, Peter DOBEŠ ${ }^{1, *}$, Juraj PIEŠ ${ }^{1}$ \\ ${ }^{1}$ Department of Railway Engineering and Track Management, Faculty of Civil Engineering, University \\ of Žilina, Univerzitná 8215/1, 01026 Žilina, Slovakia. \\ corresponding author: peter.dobes@fstav.uniza.sk.
}

\section{Abstract}

The initial part of the paper briefly characterizes the present state of the track substructure dimensioning for the non-traffic load and the necessity of updating the design map of frost indexes $I_{F d}$ as a basis for dimensioning. A substantial part of the paper is dedicated to the method of evaluating the data provided by the Slovak Hydrometeorological Institute (SHMI), and determining the dependency of design air frost indexes $I_{F d}$ on altitude for the coldest winter period in the past 50 years. The paper conclusion presents the updated design map of frost indexes and the assessment of the importance of its updating in terms of the track substructure dimensioning methodology for the non-traffic load.
\end{abstract}

\section{Keywords:}

Railway track;

Track substructure dimensioning; Non-traffic load;

Frost index;

Design map of frost indexes.

\section{Introduction}

The Slovak Railways (ŽSR) have been modernizing their tracks - parts of the Trans-European corridors for more than 18 years. In addition to the financial provision for modernizing particular track sections, it was necessary to develop relevant project documentation. The essential part of each project documentation is, besides other annexes and design justification of the track modernization, also the design and evaluation of the track substructure.

To maintain long-term safety and reliability of the track, it is necessary to secure a high-quality track skeleton as well as a sufficiently deformation-resistant track substructure. As the track skeleton is immediately placed on the track substructure, they form a single technical physical unit of railway track. An essential prerequisite of a sufficiently deformation-resistant track substructure is its correct construction arrangement, (selection of a suitable type of track substructure) and its dimensions. They subsequently guarantee the track skeleton stability as well as maintaining the required permanent state of track design and geometry.

The roadway structure and also the track substructure are subjected to long-term effects of traffic (static and dynamic) load, and non-traffic load (climate and weather effects). Some parts of the basic legislative document, which focuses on track substructure dimensioning [1], were developed on the basis of knowledge from the 1970s. In the track substructure dimensioning and evaluation procedure, it is necessary to respect new design boundary conditions, specifically:

- technical and operational requirements stated in AGC and AGTC agreements,

- application of new knowledge and technology in the field of construction,

- application of new building materials,

- global climate changes.

The Department of Railway Engineering and Track Management (DRETM) has been collecting new knowledge for updating the track substructure dimensioning methodology for non-traffic load since the beginning of the ŽSR network modernization.

Many climatologists point to a constant warming of a global climate, an increase in the average annual air temperature and a snowfall decrease. However, experimental monitoring of climatic factors 
and their influence on the thermal regime and the track substructure freezing, implemented in the DRETM facilities - track models, as well as SHMI data, indicate that every 10 years a colder (frosty) winter occurs, (approx. $70 \%$ of the maximum frost index value $I_{F}$ ). Moreover, approximately in each 20 - 25 years there is an extremely cold (frosty) winter with very low negative temperatures or long and intensive frost periods (e.g. winter periods 1960 / 1961, 1986 / 1987 and 2005 / 2006).

In the current track substructure dimensioning methodology for the non-traffic load, stated in [1], the main design parameter is the frost index $I_{F}$, always assigned to the area where the evaluated railway track is located. Due to this fact, it was necessary to verify the relevance of the frost index data in the design map of the air frost indexes $I_{F d}$ for the Slovak territory, stated in the legislative document. Thanks to the SHMI helpfulness, it was possible to collect necessary input data of mean daily air temperatures $\theta_{s}$ in the coldest winter period for the past 50 years - $1986 / 1987$. Based on these data, a respective map of design frost indexes $I_{F d}$ for the Slovak territory could be updated. Its development process is described in the following parts of this paper.

\section{Characteristics of the track substructure dimensioning methodology for the non-traffic load}

The track substructure must be able to absorb defined traffic load over time and resist the influence of the non-traffic load without harmful deformations, i.e. without defects and deficiencies of the track layout and geometry. These properties can only be guaranteed if the track structure is designed and built with a structural composition, dimensions and physical, mechanical, and thermotechnical properties of materials that consider not only the assumed geological and hydrological subgrade characteristics but also the expected effects of the traffic and non-traffic load [2].

The railway track with a conventional superstructure (gravel superstructure) forms is an open system. The subgrade surface is built of soils, which are moderately frost-susceptible to extremely frost-susceptible and at the same time poorly permeable to impermeable. Due to protection against adverse effects of precipitation water and frost, it is thus desirable to build in a protective structural layer between the ballast bed and the subgrade surface.

According to [1], the track substructure design for the non-traffic load is based on selection of a suitable protective layer material (coarse-grained, sharp-edged, with a specific grain curve), determination of its structural thickness for the most adverse season, and its water and thermal regime due to the subgrade surface soil properties.

Climatic factors (conditions), which the track substructure must be protected against, play a major role in determining the causes and effects of the track substructure defects and deficiencies. The climatic conditions are quantified by characteristics which can substantially help express their influence on the track substructure thermal regime and its depth of freezing. One of the most important characteristics of climatic conditions in a certain area is the air temperature which changes during the day and also during the year. The course of air temperatures can be expressed by the following climatic characteristics [2]:

a) average daily air temperature $\theta_{s}\left({ }^{\circ} \mathrm{C}\right)$

$\theta_{s}=\frac{\theta_{7}+\theta_{14}+2 . \theta_{21}}{4}$,

where the values $\theta_{7}, \theta_{14}$ and $\theta_{21}$ represent air temperatures measured at $7: 00,14: 00$ and $21: 00$ GMT, at $2 \mathrm{~m}$ above the ground level,

b) maximum air temperature $\theta_{\max }$ and minimum air temperature $\theta_{\min }$ in a daily or annual cycle,

c) average annual air temperature $\theta_{m}$ expressed by the relationship:

$\theta_{m}=\frac{\sum_{i=1}^{365} \theta_{s}}{365}$,

d) frost index $I_{F}\left({ }^{\circ} \mathrm{C}\right.$, day) - the maximum negative value of the sequential sum of average daily air temperatures, recorded in a respective winter period.

The frost index $I_{F}$ is the most common characteristics of the listed ones, that is used for expressing the thermal regime and track substructure evaluation for the frost damage protection. The 
frost index $I_{F}$ is determined by adding mean daily air temperatures $\theta_{s}$ in a given winter period according to the relationship:

$I_{F}=\sum_{t_{b}}^{t_{e}} \theta_{s}$,

where $t_{b}$ represents the beginning of the freezing period and $t_{e}$ represents end of the freezing period. In this way, a mass curve, expressed in ${ }^{\circ} \mathrm{C}$, day, is obtained.

The thermal regime of the track substructure is defined as a course of changes of the state of particular structural layers and subgrade soils, triggered by solar radiation, heat and temperature changes during the day or year. An important characteristic, in terms of track substructure dimensioning for the adverse effects of frost, is the depth of track substructure freezing $D_{F}$. According to [1], it can be determined from the relationship:

$$
D_{F}=0.045 \sqrt{T_{F}} .
$$

The depth of track substructure freezing can be understood as a distance of a zero isotherm $\left(0^{\circ} \mathrm{C}\right)$ from the track ballast surface (upper sleeper area).

The structural composition of the track substructure (structural thickness of a protective layer) is, from the point of view of subgrade surface protection against the adverse effects of frost, correctly designed when by achieving the design air frost index value $I_{F d}$ for the region of the evaluated section from the design map of frost indexes $I_{m, n}$ (Fig. 1) the zero isotherm does not penetrate below the subgrade surface level. (In the case of railway tracks of a lower category, according to [1], a partial freezing of subgrade surface $-D_{F, \text { allowed }}$ is allowed. Its value is based on the respective speed zone of the evaluated track section).

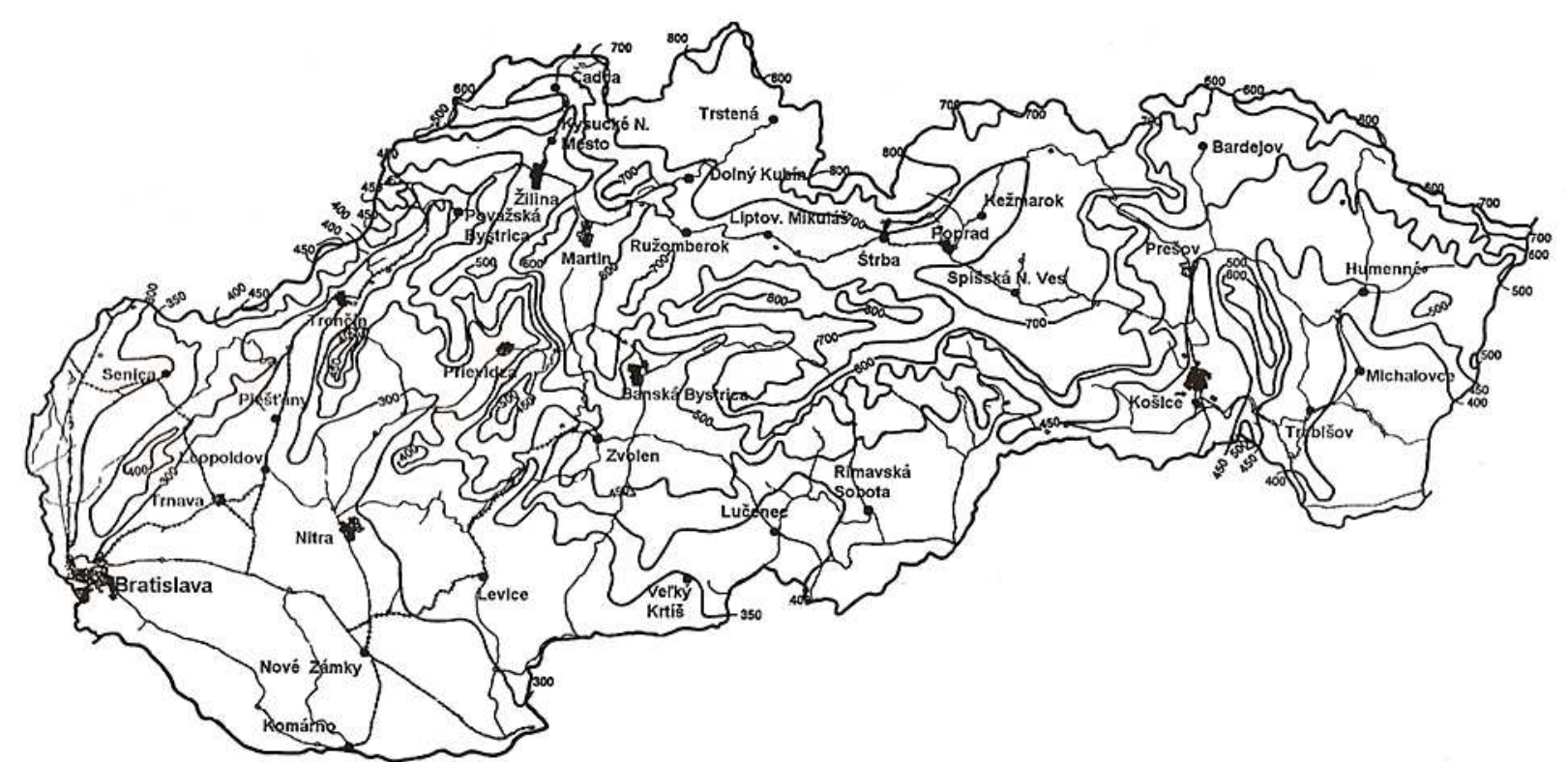

Fig. 1: Design values of the frost index $I_{F d}$ for ŽSR tracks according to [1].

The design of subgrade surface protection against the adverse effects of frost is, according to the current regulation [1], based on the determination of the required thickness of the gravel-sand layer $t_{g s}$, placed below the ballast bed level, of the supposed thickness $300 \mathrm{~mm}$, measured below the lower sleeper area. The ballast bed in the track substructure is, in this case, a part of the thermal protection of subgrade surface against the adverse effects of frost. A necessary prerequisite for the design of the required structural thickness of the protective layer, in terms of the track substructure evaluation for the adverse effects of frost, is, besides the above mentioned design frost index $I_{F d}$ of a given region, also the awareness of the water regime of subgrade surface, type of its soil in terms of its frost susceptibility and the track category - speed zone. The design of the structural gravel-sand layer (fr. $0 / 31.5 \mathrm{~mm}$ ) is implemented by nomograms. These nomograms also need to be updated 
because of the fact that at present the most used material for building the protective layer on ŽSR tracks is crushed aggregate fr. $0 / 31.5 \mathrm{~mm}, 0 / 45 \mathrm{~mm}$, or $0 / 63 \mathrm{~mm}$ and the design nomograms in [1] for determining the structural thickness are stated for gravel sand that is not used for protective or foundation layers anymore. The design nomograms for the structural thickness of the protective layer of crushed aggregate, in respect to a different thermal resistance of gravel sand $\left(\lambda=2.3 \mathrm{~W} \cdot \mathrm{m}^{-1} \cdot \mathrm{K}^{-1}\right)$ and crushed aggregate $\left(\lambda=2.0 \mathrm{~W} \cdot \mathrm{m}^{-1} \cdot \mathrm{K}^{-1}\right)$ must be included in the legislative document update [1].

Similarly, this applies for the determination of thermal conductivity coefficients $\lambda$ for all materials that are at present used for the track substructure. Our Department, within the research supported by the Slovak Ministry of Education, has been focusing on updating these nomograms and determining the thermal conductivity coefficients $\lambda$ of the track substructure materials. The research completion is planned for the final months of 2019.

\section{Updating the design map of frost indexes $I_{F d}$}

As the above mentioned dimensioning methodology, stated in [1], was developed in the 1970s, it needs to be updated in compliance with up-to-date information and knowledge (application of new materials for track substructure, possibility of using thermal insulation materials, change of climatic conditions, possibility of modelling the thermal regime of the structure using software, etc.) [3]. In respect to the fact that also the design map of frost indexes $I_{F d}$, based on the achieved frost index from the winter period $1961 / 1962$, is outdated, the following parts of the paper describe the steps and principles of its updating.

\subsection{Determination of the winter period with the lowest air frost index $I_{F}$ in 1967- 2017}

To determine the coldest (frostiest) winter period in the past 50 years, (time period used for track substructure dimensioning in [1]), the Department of Railway Engineering and Track Management, based on the data from SHMI, evaluated the achieved frost indexes $I_{F}$ from 8 Slovak meteorological stations, in 1967 to 2017. The meteorological stations were selected with the aim to cover the whole territory of Slovakia. The selection of meteorological stations for the determination of the coldest (frostiest) winter period (winter period when the highest frost index value in the Slovak territory was achieved), can be observed in Fig. 2 (green squares) [3].

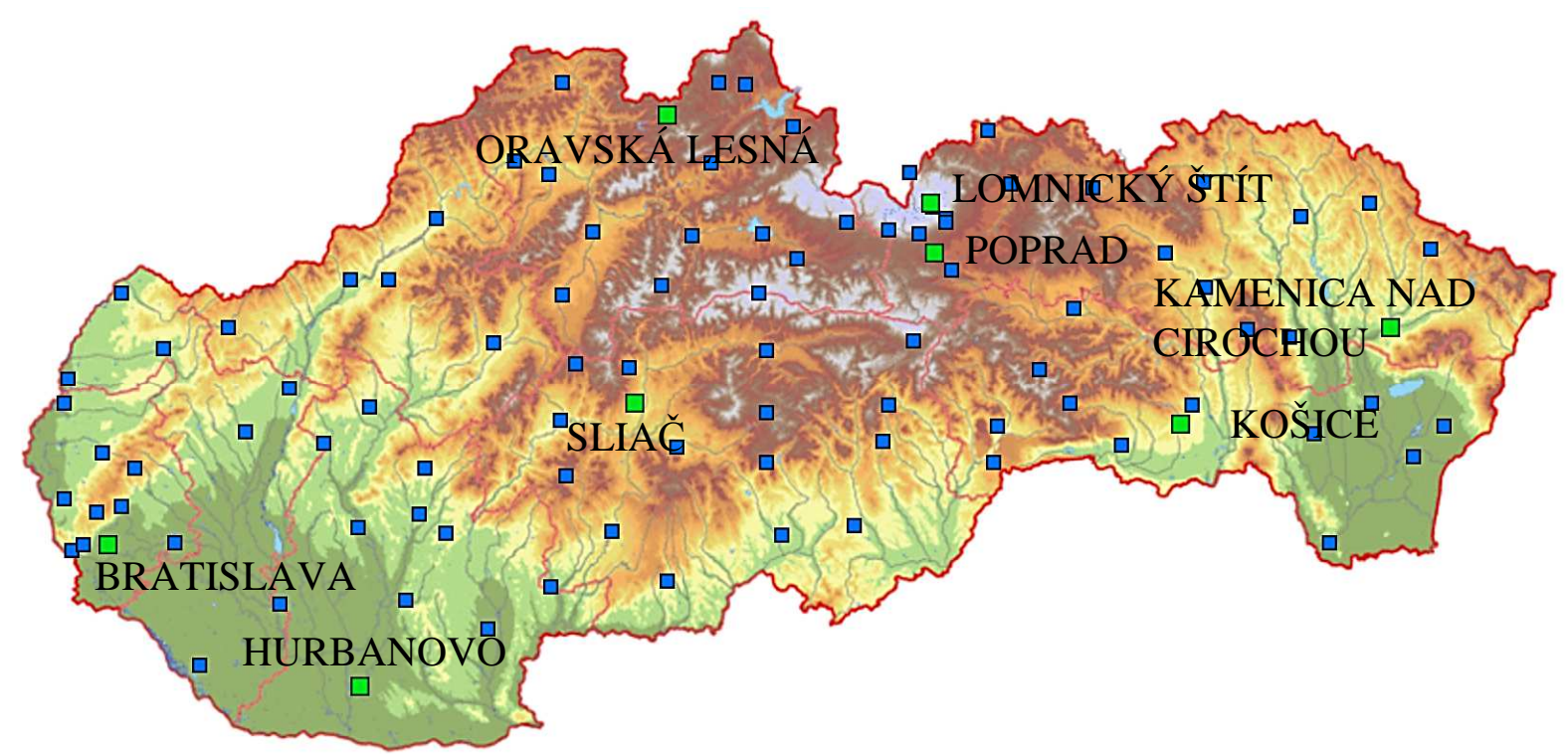

Fig. 2: Selection of stations for determining the coldest (frostiest) winter period [4].

The achieved highest air frost index $I_{F}$ values for particular meteorological stations from Fig. 2 and also the years of their achieving are demonstrated in Table 1. 
Table 1: The highest air frost index $I_{F}$ values for selected meteorological stations in 1967 - 2017 [5],

[6].

\begin{tabular}{|l|c|c|c|}
\hline \multicolumn{1}{|c|}{$\begin{array}{c}\text { Location of the } \\
\text { meteorological station }\end{array}$} & Altitude (m above sea level) & $\begin{array}{c}\text { Air frost index } \\
I_{F}\left({ }^{\circ} \mathrm{C}, \text { day }\right)\end{array}$ & Winter period \\
\hline Bratislava - airport & 133 & -259 & $1986 / 1987$ \\
\hline Hurbanovo & 115 & -252 & $1986 / 1987$ \\
\hline Kamenica nad Cirochou & 176 & -585 & $1986 / 1987$ \\
\hline Košice - airport & 230 & -510 & $1986 / 1987$ \\
\hline Lomnický štít & 2635 & -1960 & $1986 / 1987$ \\
\hline Oravská Lesná & 780 & -810 & $1986 / 1987$ \\
\hline Poprad & 694 & -741 & $1986 / 1987$ \\
\hline Sliač & 313 & -484 & $1986 / 1987$ \\
\hline
\end{tabular}

Table 1 indicates that the winter period with the highest air frost index $I_{F}$ value in the monitored 50-year period was achieved in 1986 / 1987. Due to this, SHMI also provided the necessary data for determining the frost indexes $I_{F}$ for other meteorological stations (blue squares in Fig. 2), their total number was 106. With regard to the fact that some of these meteorological stations experienced failures in data recording during the monitored winter period, the evaluation eventually included a fewer number of monitored stations.

\subsection{Dependency of frost index $I_{F}$ values on altitude}

In the first step of dependency determination of frost index values $I_{F}$ on altitude, 99 meteorological stations were involved. As the correlation coefficient indicated a low value $\left(R^{2}<0.5\right)$, the number of meteorological stations was reduced to 51 . These stations were located in towns and villages with railway infrastructure. In this case, the correlation coefficient was slightly higher, specifically $R^{2}=0.56$. For the purpose of improving mutual correlation, the dependencies of frost index values $I_{F}$ on altitude were evaluated separately, for regions of Western, Central, and Eastern Slovakia. (Fig. 3).

Based on the gained dependency relations of air frost index values $I_{F}$ and altitude, Fig. 3 was subsequently used for determining altitudes for which the air frost index $I_{F}$ achieved values -300 to $-800{ }^{\circ} \mathrm{C}$, day. It is the same range of values as in the valid design map of frost indexes, stated in [9]. These values are also demonstrated in Table 2.

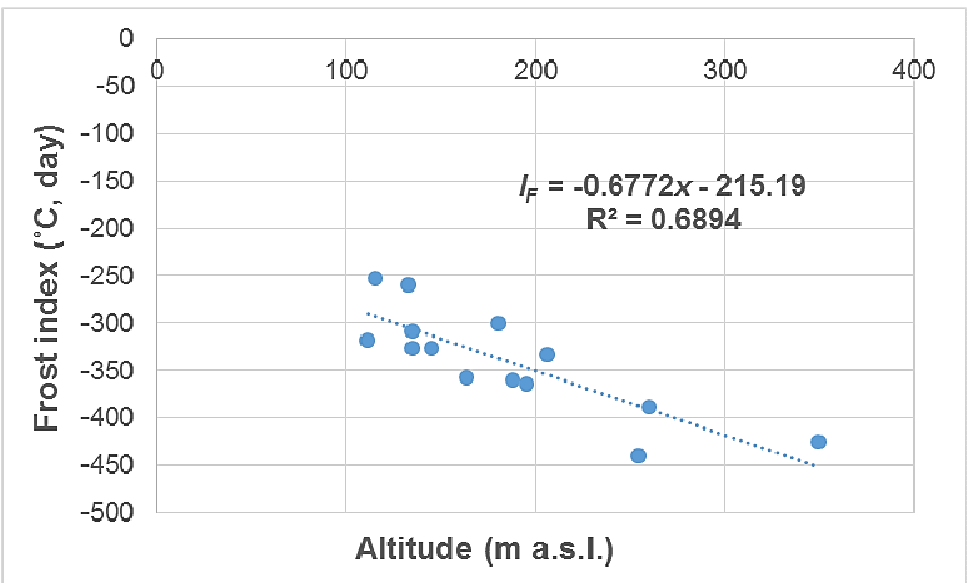

a) 


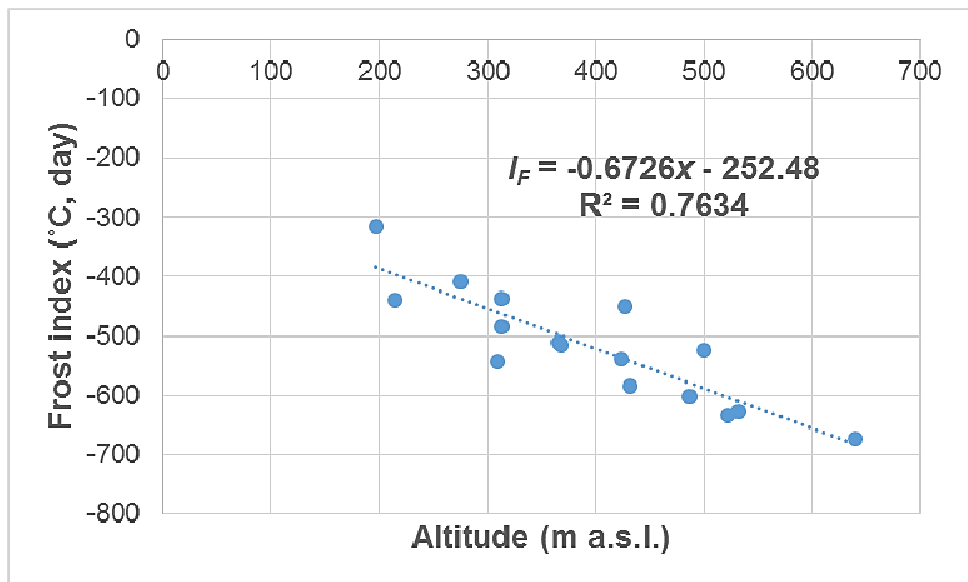

b)

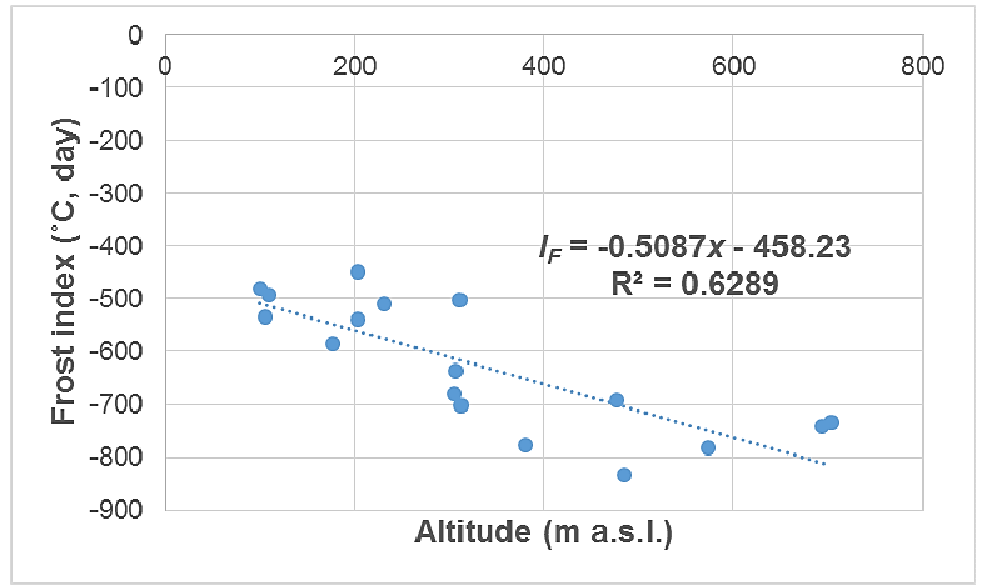

c)

Fig. 3: Dependency of frost index values on region altitude: a) Western Slovakia; b) Central Slovakia;

c) Eastern Slovakia.

Table 2: Altitudes for specific air frost index $I_{F}$ values.

\begin{tabular}{|c|c|c|c|}
\hline \multirow{2}{*}{$\begin{array}{c}\text { Air frost index } I_{F} \\
\left({ }^{\circ} \mathrm{C}, \text { day) }\right.\end{array}$} & Western Slovakia & Central Slovakia & Eastern Slovakia \\
\cline { 2 - 4 } & 120 & - & - \\
\hline-300 & 200 & 140 & - \\
\hline-350 & 270 & 220 & - \\
\hline-400 & 340 & 290 & - \\
\hline-450 & 420 & 360 & 270 \\
\hline-500 & 560 & 510 & 470 \\
\hline-600 & 710 & 660 & 670 \\
\hline-700 & 860 & 810 & - \\
\hline-800 & &
\end{tabular}

\subsection{Design map of air frost indexes $I_{F d}$ for $1967-2017$}

The update of the design map of air frost indexes $I_{F d}$ was implemented for the winter period $1986 / 1987$ - the coldest period in the past 50 years (see 3.1). Lines with identical frost index $I_{F}$ values were drawn on a map background in the 1:10 000 scale, on the basis of the dependency stated in Table 2. Then they were partially modified according to real frost index $I_{F}$ values for particular towns and villages. The updated design map of frost indexes $I_{F d}$ is shown in Fig. 4. 


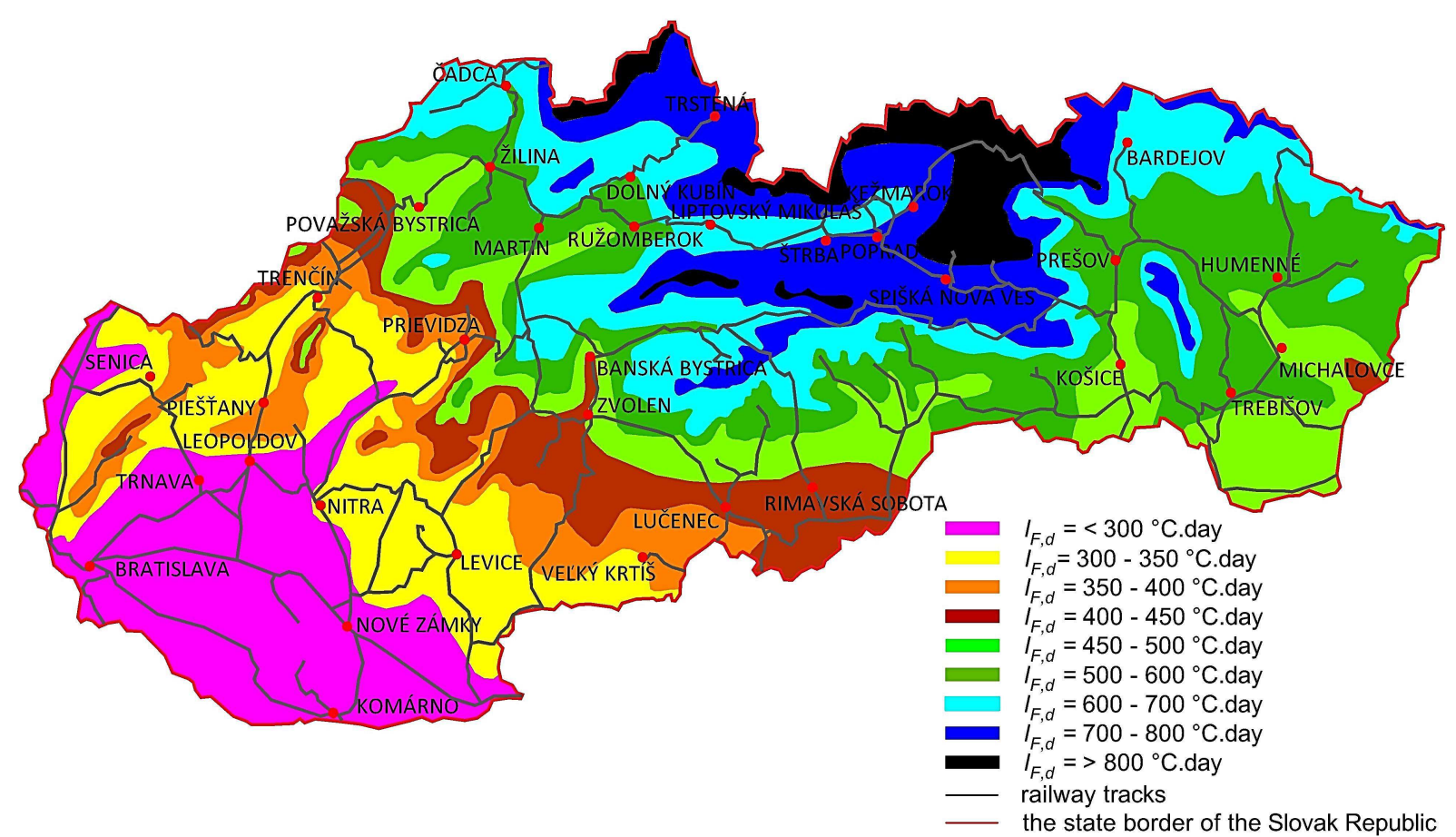

Fig. 4: Updated design map of air frost indexes $I_{F d}$ (winter period 1986 / 1987).

The comparison of the design map in Fig. 4 with the valid design map in Fig. 1 revealed that the air frost index $I_{F}$ values for some regions achieved higher values. This is caused by the fact that the design map of air frost indexes $I_{F d}$ stated in [1] is valid for the $n=0.1$ periodicity, (occurrence of the coldest or frostiest winter period once in 10 years) and the updated map is valid for the occurrence of the coldest (frostiest) winter period once in 50 years.

\section{Conclusion}

Many climatologists predict the continual warming of the Earth's climate, which corresponds to an increase in the average annual air temperature and a drop in the amount of snow cover. Despite these predictions, in the track substructure dimensioning methodology for the non-traffic load, it is still necessary to consider the occurrence of very cold (frosty) winter periods once in 20 to 25 years. As the minimum life of railway tracks is 50 years, it is suitable to consider this periodicity in the design map of frost indexes. The design map of air frost indexes $I_{F d}$, stated in Fig. 4 was also created for this periodicity. The creation of the design map of air frost indexes $I_{F d}$ in this way was supported by the fact that out of 51 air frost index $I_{F}$ values for the winter period 1986 / 1987, 40 values were higher than the values in the design map of frost indexes in [1]. 15 of them achieved a value higher in $100{ }^{\circ} \mathrm{C}$, day and 5 higher in $150{ }^{\circ} \mathrm{C}$, day.

Provided that in the track substructure dimensioning methodology for the non-traffic load according to methodology in [1] it is, under certain conditions, possible to assume partial subgrade surface $D_{F, \text { allowed }}$ freezing and its design would be implemented based on the lower value of the design frost index value $I_{F d}$, the lifetime of the structure could be significantly reduced with regard to possible greater freezing of the track substructure. The resulting track lifting in the frost period or achieving lower values of so-called spring deformation resistance in the thaw period could have greater effects on the occurrence of larger defects and deficiencies of the track layout and geometry.

As mentioned above, the update of the design map of air frost indexes $I_{F d}$ is only a partial output of the experimental activity at the Department of Railway Engineering and Track Management. The parallel research activities include updating the design map of average annual air temperatures [3], experimental monitoring of real railway track structure models [7], verification of thermo-technical parameters of selected building materials [8], and numerical modelling of various track substructures SoilVision software [9]. Moreover, further activities are conducted, with the aim to determine the input data for updating the design nomogram and the necessary update of the track substructure dimensioning methodology for the non-traffic load, included in the legislative document [1]. 


\section{Acknowledgements}

The presented results are the partial results of solving the VEGA grant project No. 1/0275/16 Structure optimization of sleeper subgrade due to non-traffic load aspect.

\section{References}

[1] TNŽ 73 6312, Design of structural layers of track substructure. GR ŽSR, Slovakia, 2005 (in Slovak).

[2] IŽVOLT, L.: Railway substructure - stress, diagnostics, design, and implementation of body construction layers of railway subgrade. Scientific monograph, University of Zilina, 2008, 324 p. (in Slovak).

[3] IŽVOLT, L. - DOBEŠ, P. - PIEŠ, J.: Contribution to the modification of input data of sub-grade structure dimensioning for non-traffic load according to the ŽSR methodology. $16^{\text {th }}$ International Conference on Railway Engineering Design \& Operation, Lisbon, Portugal.

[4] http://www.shmu.sk/sk/?page=1\&id=klimat_klimatsiet.

[5] DECKÝ, M.: Frost index evaluated from air temperature measurements since 1971 to 2006 in the territory of Slovakia. Silniční obzor, Vol. 71, No. 2, 2010, pp. 40 - 45 (in Slovak).

[6] http://www.shmu.sk/sk/?page=1069\&highlight=2075.

[7] IŽVOLT, L. - DOBEŠ, P. - PITOŇÁK, M.: Preliminary results and conclusions from the experimental monitoring of thermal regime of railway track structure. International Journal of Transport Development and Integration, Vol. 1, No. 3, 2017, pp. 529 - 539.

[8] IŽVOLT, L. - DOBEŠ, P.: Verification of thermal conductivity coefficients $\lambda$ of selected materials of railway subbase structure. Proceedings of the XXII Slovak - Polish - Russian Seminar: Theoretical Foundation of Civil Engineering, Žilina, Slovak Republic, 09. 09. 2013 - 13. 09. 2013, Moscow, Izdatel'stvo ASV, 2013, pp. 643 - 652.

[9] IŽVOLT, L. - DOBEŠ, P. - HODAS, S.: Preliminary results and conclusions from mathematical modelling of thermal regime of railway track structure. International journal of computational methods and experimental measurements, Vol. 4, No. 2, 2016, pp. 69 - 79. 